УДК 622.692.4.07

\title{
РАЗРАБОТКА КОНСТРУКЦИИ ОПОРЫ ДЛЯ ПОДЗЕМНОГО КРЕПЛЕНИЯ ТРУБОПРОВОДА В ЗОНАХ РАСПРОСТРАНЕНИЯ ОСТРОВНОЙ И ПРЕРЫВИСТОЙ МЕРЗЛОТЫ
}

\author{
Шамилов Хирамагомед Шехмагомедович1, \\ khiramagomed@mail.ru
}

\section{Султанмагомедов Тимур Султанмагомедович1, tsultanmaga@gmail.com}

\section{Султанмагомедов Султанмагомед Магомедтагирович1, ftt2010@mail.ru}
1 Уфимский государственный нефтяной технический университет, Россия, 450064, г. Уфра, ул. Космонавтов, 1.

\begin{abstract}
Актуальность исследования обусловлена необходимостью разработки эфффективных технологий для обеспечения сохранности проектного положения участков магистрального трубопровода в районах с несплошным характером распространения мерзлоты. Особую актуальность работа имеет с учетом активного освоения северньх и арктических нефртегазоносных районов России.

Цель: разработать проектное решение и конструкцию подземных опор для закрепления нетеплоизолированных участков газопровода в сезонно-тающих и многолетнемерзлых грунтах при островном характере мерзлоты.

Объекты: магистральный трубопровод, закрепленный в мерзлых грунтах.

Методы: анализ и систематизация российского и зарубежного опыта теоретических и практических исследований, аналитические расчеты и компьютерное моделирование с применением программного обеспечения ANSYS на основе современных положений строительной механики и теории упругости.

Результаты. Рассмотрены существующие типы опор и подвесок трубопроводов в разрезе их применимости для целей крепления подземных участков нефте- и газопроводов в многолетнемерзлых и сезонно-тающих грунтах, в том числе в местах пересечения островной мерзлоты, ледяных линз и бугров пучения. По результатам выполненного анализа возможных нагрузок и ограничений уже существующих опорных конструкций трубопроводов при рисках вспльтия и провисания подземных участков в протаявшей траншее предложена конструкция подземных анкерных опор и сделаны выводы о преимуществах их применения. Для расчета нагрузок и определения требуемых размеров и количества анкеров, сечений тросов растяжек и хомута для крепления трубопровода была разработана конечно-элементная модель, эфффективность которой подтверждена аналитическим путем и экспериментально на разработанном испьтательном стенде.
\end{abstract}

\section{Ключевые слова:}

Анкерная опора трубопровода, расчеты конструкции, подземный газопровод, островная мерзлота, сезонно-тающие грунты, ледяная линза, бугор пучения, устойчивость.

\section{Введение}

Зоны многолетней мерзлоты занимают не менее $60 \%$ общей территории Российской Федерации, что составляет порядка 10 млн км². Общая площадь территории Земли с многолетнемерзлыми грунтами (сплошного, прерывистого и островного распространения) - 35 млн км², что составляет около 23 \% участков суши.

Строительство и эксплуатация трубопроводов в районах распространения мерзлых грунтов сопряжены с проблемами, обусловленными климатическими и инженерно-геокриологическими условиями местности, а также степенью техногенного вмешательства в природную среду. Проблемы вызваны температурным влиянием трубопровода на мерзлые породы, что приводит к возникновению и развитию опасных инженерно-геологических процессов: пучение и просадка грунтов, обводнение трассы, образование таликов и пр. Эффект теплового воздействия магистрального газопровода как мощного источника тепла в сочетании с положительной плавучестью в слабонесущих грунтах приводят к потере балластирующей способности последних, увеличению ареола протаивания и, как следствие, к всплытию или просадке незакрепленных участков трубопровода.
Оттаивание мерзлых льдистых пород вокруг подземного магистрального трубопровода приводит к смещению его оси. Если объем оттаявшего грунта имеет значительную величину, это может привести и к просадке поверхности земли. После укладки и засыпки грунтом над трубой образуется маломощный слой сезонно-мерзлых пород. Этот слой оттаивает быстрее сезонно-мерзлых и сезонно-талых окружающих пород, которые не были затронуты строительными работами. По мере таяния снега разгрузка снеговых вод происходит именно через талые породы в траншее трубопровода. Если оттаивание маломощных мерзлых пород носит серьезный характер, это чревато повышением уровня грунтовых вод и подтоплением траншеи.

На трассе трубопровода глубина сезонного оттаивания грунта неминуемо повышается. Это связано с увеличением солнечной радиации из-за удаления растительности. Если грунты вблизи трубопровода тают неравномерно, повышается вероятность его перемещений. Если же тают грунты в основании трубопровода, деформации трубопровода могут быть весьма опасны, так как грунты в этом случае могут проседать не только вследствие таяния включений льда, но и из- 
за уплотнения оттаявшего грунта под воздействием давления собственного веса и внешних нагрузок.

Для снижения влияния вышеизложенных опасностей необходимо обратить внимание на следующее:

- магистральный трубопровод является инженерным сооружением большой протяженности и проходит через участки, отличающиеся инженерногеокриологическими условиями;

- на трассе трубопровода могут протекать различные грунтово-мерзлотные процессы, которые могут негативно проявиться в виде термокарстов, бугров пучения, оттаивания пластовых льдов, наледей и пр.;

- может быть нарушен водно-тепловой баланс района строительства и естественная миграция вод.

Закрепление трубопроводов большого диаметра в многолетнемерзлых грунтах само по себе представляет еще одну инженерную задачу. В зависимости от сезонности и толщи мерзлоты опорные конструкции и участок трубопровода испытывают различные знакопеременные нагрузки, что требует проведения тщательных расчетов при выборе количества и шага расстановки опор, не только из условия обеспечения несущей способности, но также с учетом напряженнодеформированного состояния закрепляемого участка трубопровода. Выбор типов конструкций используемых опор, их размеров и количества должен отвечать условиям надежности и технико-экономической эффективности.

\section{Анализ существующих технологических решений для закрепления подземного трубопровода в мерзлых грунтах}

Первый опыт прокладки магистрального трубопровода в зонах распространения многолетнемерзлых грунтов относится к Трансаляскинскому нефтепроводу (США). На сегодняшний день уже накопился колоссальный опыт прокладки и эксплуатации линейных объектов в инженерно-геологических условиях, осложненных многолетней мерзлотой, как в России, так и за рубежом. Тем не менее вопросы техникоэкономического обоснования метода прокладки для участков трассы в районах распространения островной мерзлоты сохраняют свою актуальность. Эти вопросы стоят особенно остро на стадии предпроектных работ в ходе реализации инвестиционных проектов, в условиях недостатка исходных данных из-за отсутствия результатов инженерных изысканий и данных геомониторинга. Исследования в данном направлении для нашей страны сегодня являются особенно актуальными ввиду активного освоения северных и арктических районов и процессов, которые протекают в многолетнемерзлых грунтах из-за глобального потепления [1-5].

Основные требования по обеспечению устойчивости и эксплуатационной надежности магистральных трубопроводов внесены в нормативные документы по инженерным изысканиям и проектированию [6-9]. Но они не дают исчерпывающих ответов на все проблемные вопросы и требуют многочисленных исход- ных данных, которые могут быть получены только путем длительного мониторинга или же по результатам анализа эксплуатации других подобных объектов в близких условиях.

В работах $[10,11]$ представлен анализ рисков эксплуатации и недостатки существующих методов прокладки магистральных трубопроводов в сезоннотающих и многолетнемерзлых грунтах, а также предложена конструкция свайной опоры для подземного закрепления участков в зонах прерывистой (островной) и сезонно-тающей, в том числе линзовой, мерзлоты.

В рамках исследования проанализированы существующие типы конструкций для крепления трубопроводов различного назначения, которые в общем случае делятся на опоры и подвески.

Первый вид - шарнирного типа, используется только для надземной прокладки, так как из-за своей сложной конструкции не способны работать в грунте, тем более мерзлом, вторые - подвески, компенсируют только лишь просадки грунта и не работают при выталкивающих нагрузках.

Несмотря на обилие конструкций и многолетний опыт эксплуатации нефте- и газопроводов, проложенных в сложных инженерно-геологических и климатических условиях (преимущественно надземного исполнения) [12-15], вопрос подземного точечного закрепления отельных участков незначительной протяженности при пересечении ледяных линз и бугров пучения все еще открыт и требует разработки как проектных, так и технических решений $[16,17]$.

Так, к примеру, конструкция подвесной опоры для магистрального нефтепровода, разработанная ПАО «Транснефть» [18] для осложненных просадками участков прокладки, не может компенсировать нагрузок при всплытии подземного участка в обводненной траншее после оттаивания мерзлых пород.

В теплоэнергетической отрасли существуют более сложные подвесные опоры, отличающиеся наличием пружинного натяжителя подвесной части опоры, который в том числе препятствует всплытию трубы. Однако данная конструкция подразумевает ее полуподземное расположение так, чтобы пружинаамортизатор находилась на поверхности, что потребует значительного увеличения объемов земельных работ, сильно усложнит процесс проектирования трассы и приведет к удорожанию строительства.

Довольно эффективными в зонах островной мерзлоты для сохранения подземного способа прокладки могут быть решения, разработанные для закрепления участков трубопроводов в слабонесущих грунтах [19]. При этом контейнерные методы, из-за меньшей надежности при изменениях проектного положения и необходимости привоза минерального грунта, в данном случае не рекомендуются к применению, хотя и могут быть использованы при незначительной протяженности трассы и глубине укладки. Лучшим же решением будет применение свайных конструкций из анкерных опор в исполнениях для мерзлого грунта с гибкими растяжками. 
В мировой практике в разные годы имели место исследования в области повышения несущей способности мерзлых грунтов при помощи вакуумных устройств, колонн с контролируемым модулем, геосинтетической арматуры, цементирования грунта и укрепляющих волокон. Каждый из упомянутых методов наделен своими преимуществами и при нейтрализации слабых сторон в будущем может найти применение в деле повышения надежности магистральных трубопроводов [20-22].

\section{Новая конструкция опоры для подземного} крепления трубопровода

Как уже отмечалось ранее, в рамках проводимых исследований, получен патент для устройства точечного закрепления подземных участков трассы в зонах распространения островной мерзлоты [23]. Предложена конструкция опор на свайном основании, которая представлена на рис. 1 .

При установке опор после рытья траншеи буровым механизмом пробуривают скважины для свай, они устанавливаются попарно через определенный промежуток по обе стороны трубопровода таким образом, чтобы конденсатор сезонно-действующего охлаждающего устройства (термостабилизатора) находился выше уровня поверхности земли. Бурона- бивные сваи забиваются в мерзлые грунты на удалении от прогнозируемого ареола оттаивания, на случай интенсивного теплопритока к сваям предусмотрена подача охлаждающего агента в сезонно-действующее охлаждающее устройство для термостабилизации грунта основания свай. Шаг установки опор и необходимые параметры сваи (длина, диаметр, армирование, производительность термостабилизатора) определяются при помощи расчета в каждом конкретном случае. Затем на трубопровод при помощи грузоподъемного средства с использованием шпилек монтируется металлический хомут. Хомут выполнен разъемным и состоит из двух половин трубы большего диаметра. Через петли хомута пропускаются два стальных троса, огибая трубопровод снизу и сверху. Концы стального троса пропускают через ушко талрепа в исполнении «вилка-ушко», загибаются в петлю и закрепляются зажимами. Вилка талрепа крепится к проушине закладного элемента, который устанавливается на буронабивную сваю с помощью болтовых соединений. Натяжение стальных тросов и положение трубопровода регулируется талрепами. После монтажа трубопровод и опорную конструкцию засыпают грунтом.
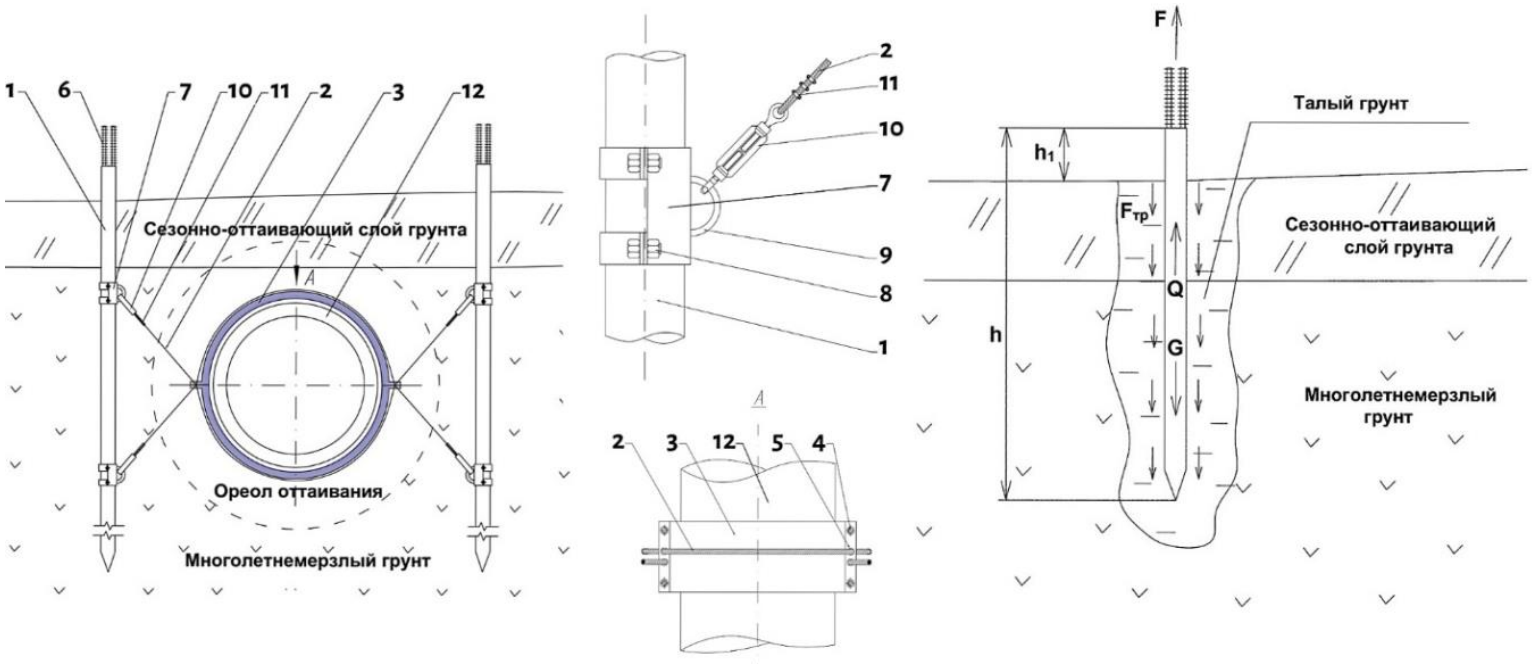

Pис. 1. Подземная анкерная опора для закрепления трубопровода: 1 - буронабивные сваи; 2 - стальные тросы; 3 хомут; 4 - шпильки; 5 - петли; 6 - термостабилизаторы; 7 - закладной элемент; 8 - болтовое соединение; 9 - проушина; 10 - талреп; 11 -зажим

Fig. 1. Underground anchor support for fixing the pipeline: 1 - bored pile; 2 -steel cables; 3 -clamp; 4 -studs; 5 - collar loops; 6 - thermostabilizers; 7 - mortgage element; 8 - bolt connection; 9 - eye of a mortgage element; 10 turnbuckle; 11 - clip of a steel cable

В процессе эксплуатации магистрального трубопровода вокруг него появляется ореол оттаивания, но проектное положение сохраняется благодаря тому, что конструкция опоры позволяет противостоять как просадкам грунта, так и всплытию трубопровода в обводненной траншее, а буронабивные сваи уходят глубже ореола оттаивания.

\section{Методика исследования}

Для определения необходимых геометрических параметров предложенной конструкции свайных опор были рассчитаны размеры анкерных устройств (свай) исходя из серийно выпускаемой продукции (значение наружного диаметра от 32 до 377 мм) (рис. 2, слева). При расчете удерживающей способности анкерного устройства в зависимости от длины (рис. 2, справа) приняты следующие исходные данные: высота надземной части сваи $\mathrm{hl}=200$ мм, толщина стенки $\delta=4$ мм и диаметр несущей трубы $\mathrm{D}_{\mathrm{a}}=219$ мм. При расчетах принято допущение, что грунт в местах крепления анкерных устройств полностью растеплен, то есть удерживающая способность его минимальна. 

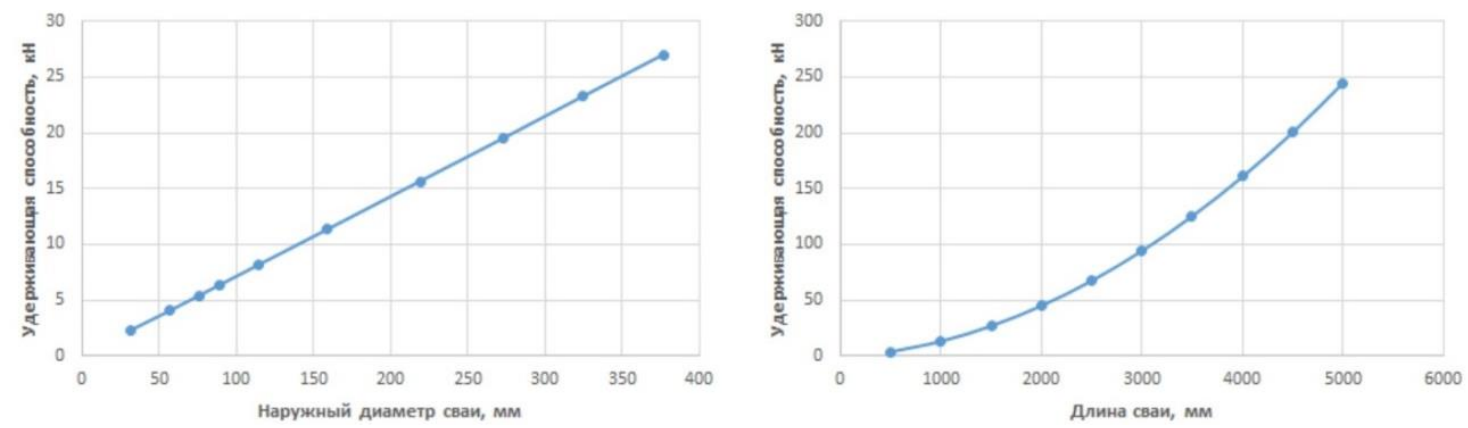

Pис. 2. Результаты расчета требуемых размеров анкерных устройств

Fig. 2. Calculation results of the required dimensions of the anchor devices

Удерживающая способность сваи составляется действиями двух сил - собственного веса сваи и силы трения о грунт внешней поверхности сваи:

$$
F=G+F_{\text {тр }}-Q,
$$

где $G$ - собственный вес сваи (анкера), $\mathrm{H} ; F_{\text {тр }}$ - сила трения сухого грунта о поверхности сваи (анкера), $\mathrm{H} ; Q-$ подъемная (выталкивающая) сила грунтовых вод, Н.

Рассмотрим каждый из перечисленных силовых факторов, в совокупности определяющих расчётную удерживающую способность (одного анкера).

Собственный вес сваи:

$$
G=0,25 \cdot \pi \cdot\left(D_{\mathrm{H}}^{2}-D_{\mathrm{BH}}^{2}\right) \cdot h \cdot \gamma_{\mathrm{M}},
$$

где $D_{\text {н }}$ и $D_{\text {вн }}-$ внешний и внутренний диаметр сваи, м; $h$ - длина сваи, м; $\gamma_{\text {м }}$ величина удельного веса металла стенки, кг/м².

Силы трения (сцепления грунта) о цилиндрические поверхности анкеров свайного основания вычисляются следующим образом:

$$
F_{\text {тр }}=S_{\text {н }} \cdot \tau_{\text {акт }}=\pi \cdot D_{\mathrm{H}} \cdot\left(h-h_{1}\right) \cdot \tau_{\text {акт }},
$$

где $S_{\text {н }}$ - площадь наружной поверхностей сваи, контактирующей с грунтом, м²; $h_{1}$ - высота сваи, выступающая над поверхностью грунта, м; $\tau_{\text {акт }}-$ касательное напряжение на поверхности сваи, Па, находится по следующей формуле:

$$
\tau_{\text {акт }}=e_{\text {акт }} \operatorname{tg} \varphi=\left[\begin{array}{c}
\gamma_{\text {гр }}\left(h-h_{1}\right) \operatorname{tg}^{2}\left(45^{\circ}+\frac{\varphi}{2}\right)+ \\
+2 c \cdot \operatorname{tg}\left(45^{\circ}+\frac{\varphi}{2}\right)
\end{array}\right] \operatorname{tg} \varphi,
$$

где $\varphi$ - расчетное значения угла внутреннего трения сухого грунта, град.; $c$ - коэффициент сцепления грунта; $\gamma_{\text {гр }}$ - значение удельного веса сухого грунта, $\mathrm{H} / \mathrm{M}^{3}$.

Расчетная выталкивающая сила воды (подъёмная сила), действующая на один анкер (в основании их может быть несколько), обусловленная архимедовой силой:

$$
Q=\pi \cdot g \cdot \frac{D_{\mathrm{H}}^{2}-D_{\mathrm{BH}}^{2}}{4} \cdot h \cdot \rho_{\mathrm{B}},
$$

где $g$ - значение ускорения свободного падения, м/ $\mathrm{c}^{2}$; $\rho_{\theta}-$ плотность грунтовой воды с учетом растворен-

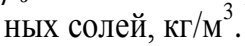

Расчеты показали, что длина анкера, как и следовало ожидать, является определяющей для несущей способности. Количество анкеров для одной опоры принято с двукратным запасом - для обеспечения ее надежности, то есть не менее четырех точек крепления вне зависимости от глубины заглубления, веса трубы и шага опор (потенциально возможной величины пролета).

\section{Компьютерное моделирование}

Для максимальных нагрузок (при допустимой величине пролета - шаге расстановке опор, принятом в расчетах 100 м), действующих на отклонившийся от проектного положения подземный участок газопровода Ду1200, в программной системе конечноэлементного анализа ANSYS были определены значения продольных напряжений, возникающих в опасном сечении стенки трубы, и эквивалентных нагрузок в сечении хомута (рис. 3,4 , табл. 1 ).
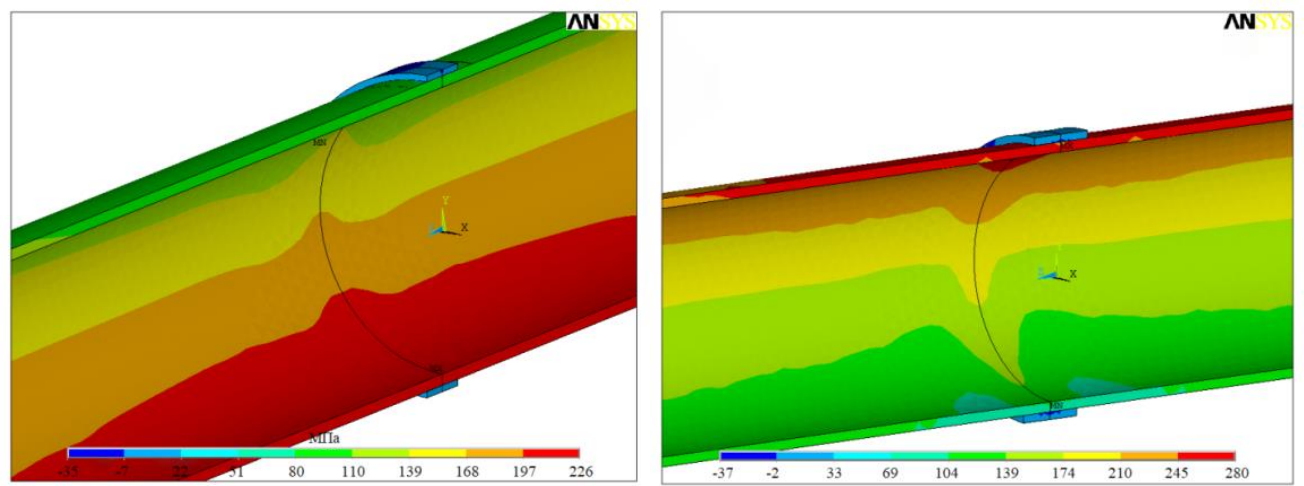

Рис. 3. Распределение продольных напряжений в опасном сечении трубы при всплытии и провисании подземного газопровода Ду1200

Fig. 3. Longitudinal stresses distribution in the dangerous section of the pipe during the ascent and sagging of the underground gas pipeline DN1200 

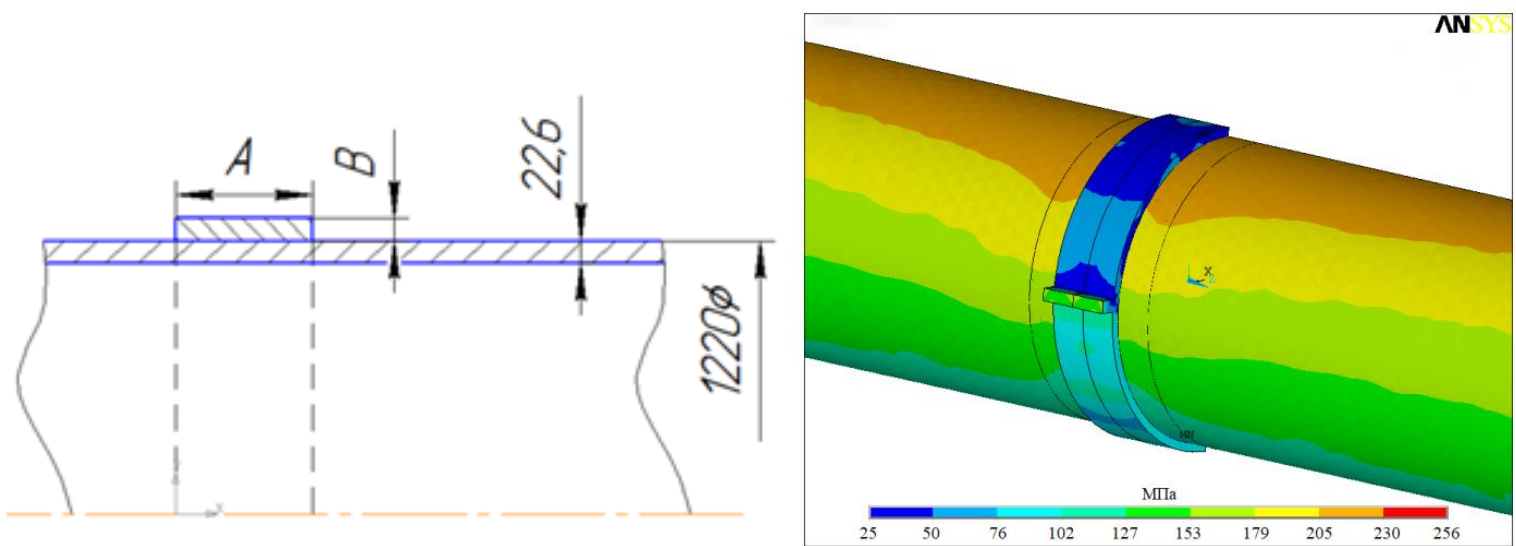

Pис. 4. Эквивалентные напряжения в сечении хомута опоры

Fig. 4. Equivalent stresses in the cross section of the support clamp

Таблица 1. Результаты расчета эквивалентных напряжений в хомуте в зависимости от его размеров

Table 1. Results of calculation of equivalent stresses in the clamp depending on its size

\begin{tabular}{|c|c|c|c|c|c|}
\hline 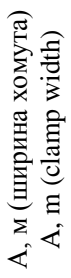 & 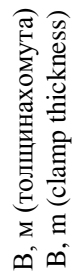 & 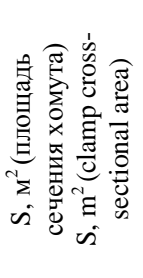 & 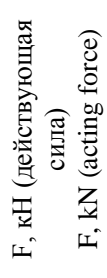 & 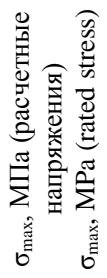 & 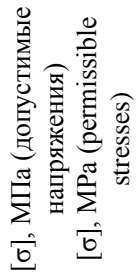 \\
\hline 0,1 & 0,015 & 0,0015 & 184 & 1730 & 300 \\
\hline 0,3 & 0,015 & 0,0045 & 184 & 301 & 300 \\
\hline 0,5 & 0,015 & 0,0075 & 184 & 182 & 300 \\
\hline 0,1 & 0,025 & 0,0025 & 184 & 480 & 300 \\
\hline 0,3 & 0,025 & 0,0075 & 184 & 120 & 300 \\
\hline 0,5 & 0,025 & 0,0125 & 184 & 109 & 300 \\
\hline 0,1 & 0,035 & 0,0035 & 184 & 225 & 300 \\
\hline 0,3 & 0,035 & 0,0105 & 184 & 85,2 & 300 \\
\hline 0,5 & 0,035 & 0,0175 & 184 & 69,8 & 300 \\
\hline
\end{tabular}

С учетом максимальных нагрузок были определены требуемые геометрические размеры хомута и расчетные диаметры тросов гибких растяжек (рис. 5, табл. 2).

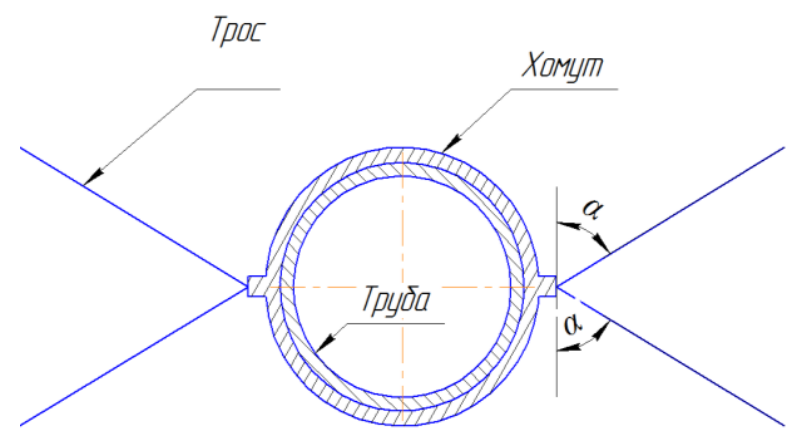

Рис. 5. Расчетная схема для определения требуемого сечения тросов

Fig. 5. Design scheme for determining the required crosssection of the cables

В табл. 2 приведены результаты расчета минимального диаметра троса в зависимости от его марки- ровочной группы при отклонении газопровода в вертикальной плоскости от проектного положения (схемы на рис. 4, 5).

Таблица 2. Результаты расчета минимального диаметра троса растяжек

Table 2. Results of calculation of the cable extensions minimum diameter

\begin{tabular}{|c|c|c|c|c|c|}
\hline \multirow[t]{2}{*}{$\begin{array}{c}\alpha, \text { граду- } \\
\text { сы } \\
\alpha, \text { degrees }\end{array}$} & \multirow[t]{2}{*}{$\begin{array}{l}\mathrm{F}, \mathrm{\kappa H} \\
\mathrm{F}, \mathrm{kN}\end{array}$} & \multicolumn{4}{|c|}{$\begin{array}{c}\text { Диаметр троса растяжек опоры (мм) } \\
\text { в зависимости от его маркировочной } \\
\text { группы, МПа } \\
\text { Diameter of a support cable of extensions (mm) } \\
\text { depending on its marking group, MPa }\end{array}$} \\
\hline & & 1600 & 1700 & 1800 & 2000 \\
\hline 0 & 183,7 & 17,1 & 16,6 & 16,1 & 15,3 \\
\hline 15 & 190,2 & 17,4 & 17,4 & 16,9 & 16,4 \\
\hline 30 & 212,1 & 18,4 & 18,4 & 17,8 & 17,3 \\
\hline 45 & 259,7 & 20,3 & 20,3 & 19,7 & 19,2 \\
\hline 60 & 367,1 & 24,2 & 24,2 & 23,5 & 22,8 \\
\hline
\end{tabular}

Проведенные расчеты показали возможность использования в качестве основания подземной опоры двух буронабивных свай (анкеров для мерзлых грунтов). Для исключения возможности появления ореола оттаивания вокруг сваи предлагается термостабилизировать грунт путем установки в них сезоннодействующих охлаждающих устройств, полости которых заполнены низкокипящим агентом, с последующим регулярным термомониторингом трассы.

Расчеты прочности сечения хомута для крепления трубы к растяжкам опоры показали следующие минимально необходимые толщины стального листа: для хомута шириной $0,1 \mathrm{~m}-35$ мм, для $0,3 \mathrm{~m}-25 \mathrm{мм}$ и для 0,5 м - 15 мм. Требуемые минимальные диаметры тросов растяжек опоры газопровода Ду1200 составили 22,8-24,2 мм в зависимости от его маркировочной группы.

При доработке предложенной конструкции опоры путем установки двух дополнительных свай аналогичных геометрических размеров, по одной с каждой стороны, тяговые усилия на тросы будут снижены вдвое, также вдвое повысится и несущая способность опоры, что обеспечит закрепление оси трубопровода даже при срыве или растеплении грунтов под одной из свай. 
Стоит отметить, что представленные результаты численного исследования получены с учетом принятого допущения об отсутствии взаимодействия трубопровода и грунтового массива в пределах ареола его оттаивания и расположения свай, основанием для которых служила сплошная ледяная линза как наиболее опасный расчетный случай.

\section{Экспериментальная апробация опоры и разработанной цифровой модели закрепленного подземного участка трубопровода}

Для проверки работоспособности конструкции и результатов расчета модели в ANSYS была создана экспериментальная установка (рис. 6). Установка моделирует работу в грунте подземной анкерной опоры для закрепления трубопровода. Установка состоит из неподвижной и подвижной рамок, с помощью которых мы можем задавать необходимое значение деформации трубы. Подвижная рама имитирует буронабивные сваи. Значение ее перемещения контролируется нагружающим болтом. Под нагружающим болтом установлен тензодатчик. К подвижной раме с помощью стальных тросов прикреплена муфта, выполняющая роль хомута. Как и в анкерной опоре, тросы огибают муфту сверху и снизу, проходя через ее проушины. Муфта установлена на трубу меньшего диаметра. Концы трубы жестко прикреплены к неподвижной раме. Для эксперимента выбрана труба $35 \times 1,5$ из стали $08 \mathrm{X} 18 \mathrm{H} 10$ длиной 2 м. Экспериментальная установка моделирует нагрузки и перемещения как при всплытии в обводненной траншее, так и при провисании участка в термокарсте, основной целью стендовых испытаний является подтверждение результатов численных экспериментов, полученных по разработанной модели конечных элементов.

Во время проведения эксперимента, моделируя всплытие трубопровода в обводненной траншее, рамка с моделью свайных опор перемещалась вверх, относительно основной рамы на 0,01 м. Усилие, необходимое для изгиба оси трубы, фиксировалось показаниями с тензодатчиков (рис. 7).

При этом для проверки работоспособности ранее использованной математической модели для расчета конструкции опоры в среде ANSYS сравнивались как результаты прямых аналитических расчетов, так и данные тензометрических измерений с фактическими перемещениями оси трубы, задаваемыми рамкой (табл. 3).

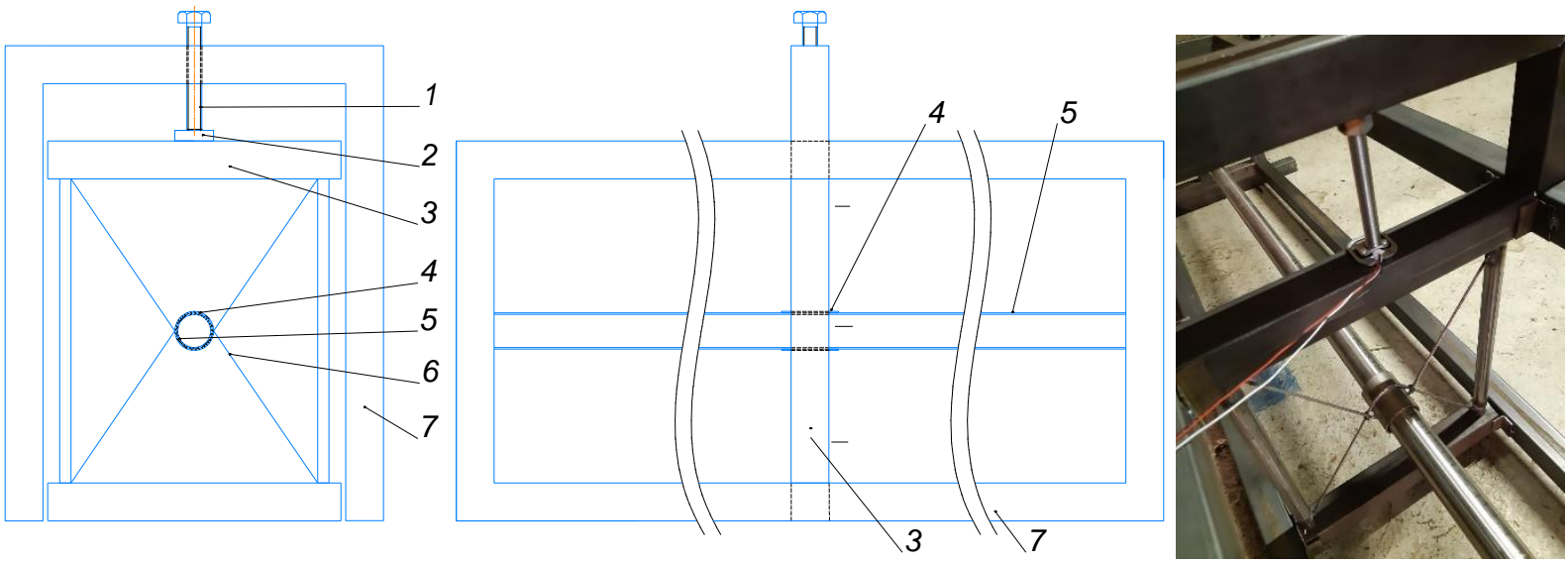

Рис. 6. Общий вид и схема экспериментальной конструкции: 1 - нагружающий болт; 2 - датчик; 3 - подвижная рама; 4 -муфта; 5 - труба; 6- трос; 7 -основная неподвижная рама

Fig. 6. General view and the experimental design scheme: 1 - loading bolt; 2 -sensor; 3 - movable frame; 4 - coupling; 5 pipe; 6 - cable; 7 - main fixed frame
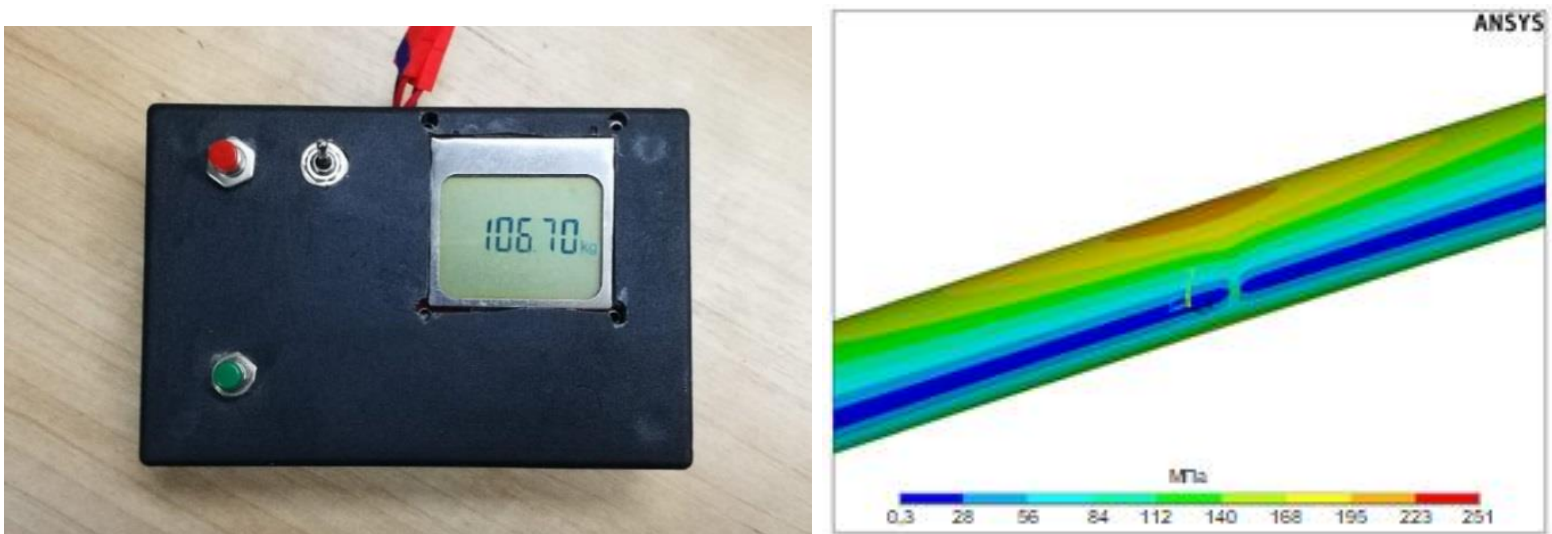

Рис. 7. Сопоставление результатов моделирования и опытных замеров

Fig. 7. Comparison of simulation results and experimental measuring 
Таблица 3. Результаты проверки работоспособности расчетной модели

Table 3. Results of checking the correctness of the calculation model

\begin{tabular}{|c|c|c|c|}
\hline $\begin{array}{l}\text { № oпыта } \\
\text { Experiment no. }\end{array}$ & $\begin{array}{l}\text { Подъёмная сила, } \mathrm{H} \\
\text { Lift force, } \mathrm{N}\end{array}$ & $\begin{array}{l}\text { Напряжения, МПа } \\
\text { Stress, MPa }\end{array}$ & $\begin{array}{l}\text { Перемещения, мм } \\
\text { Displacement, mm }\end{array}$ \\
\hline \multicolumn{4}{|c|}{$\begin{array}{c}\text { Результаты прямого аналитического расчета (исходные данные - величина подъемной силы при моделировании в ANSYS) } \\
\text { Results of analytical calculation (initial data - the magnitude of the lifting force from ANSYS modeling) }\end{array}$} \\
\hline 1 & 1109,54 & 218 & 10,5 \\
\hline 2 & 554,77 & 109 & 5,25 \\
\hline 3 & 277,385 & 54,5 & 2,6 \\
\hline \multicolumn{4}{|c|}{$\begin{array}{c}\text { Результаты расчета в конечно-элементной модели ANSYS (исходные данные - заданные фактические перемещения оси трубы) } \\
\text { Calculation results in the finite element model ANSYS (initial data - given actual displacements of the pipe axis) }\end{array}$} \\
\hline 1 & 1109,54 & 215 & 10 \\
\hline 2 & 554,77 & 107,5 & 5 \\
\hline 3 & 277,385 & 53,75 & 2,5 \\
\hline \multicolumn{4}{|c|}{$\begin{array}{c}\text { Результаты измерений с тензометрических датчиков (исходные данные - заданные фактические перемещения оси трубы) } \\
\text { Measurement results with strain gauges (initial data - given actual displacements of the pipe axis) }\end{array}$} \\
\hline 1 & $1045,66(106,7$ кг $/ \mathrm{kg})$ & - & 10 \\
\hline 2 & 516,006 & - & 5 \\
\hline 3 & 259,965 & - & 2,5 \\
\hline
\end{tabular}

Из результатов прямых и обратных поверочных расчетов видно, что надёжность конструкции подземной опоры трубы подтверждается высокой сходимостью модели с аналитическими зависимостями и опытными замерами.

\section{Заключение}

Представленные в статье результаты аналитических, численных и экспериментальных исследований позволили установить, что предложенная в [23] конструкция опоры позволяет обеспечить эффективное

\section{СПИСОК ЛИТЕРАТУРЫ}

1. An observation based constraint on permafrost loss as a function of global warming / S.E. Chadburn, E. Burke, P. Cox, P. Friedlingstein, G. Hugelius, S. Westermann // Nature Climate Change. - 2017. - V. 7. - Iss. 5. - P. 340-344.

2. Geophysical imaging of permafrost and talik configuration beneath a thermokarst lake / Yanhui You, Qihao Yu, Xicai Pan, Xinbin Wang, Lei Guo // Permafrost and Periglacial Processes. 2017. - V. 28. - P. 470-476

3. Lewkowicz A.G., Way R.G. Extremes of summer climate trigger thousands of thermokarst landslides in a high Arctic environment $/$ Nature Communications. - 2019. - V. 10 (1):1329. URL: https://doi.org/10.1038/s41467-019-09314-7 (дата обращения 17.04.2020).

4. Ford J.D., McDowell G., Jones J. The state of climate change adaptation in the Arctic // Environmental Research Letters. 2014. - V. 9 (104005). URL: https://iopscience.iop.org/article/ 10.1088/1748-9326/9/10/104005 (дата обращения 17.04.2020).

5. Van Huissteden J. Thawing permafrost: permafrost carbon in a warming Arctic. - Cham: Springer Nature Switzerland AG, 2020. $-39 \mathrm{p}$

6. СП 36.13330.2012 Магистральные трубопроводы. Актуализированная редакция СНиП 2.05.06-85* (с Изменениями № 1, 2). М: Стандартинформ, 2019. - $46 \mathrm{c}$.

7. СП 25.13330.2012 Свод правил «СНиП 2.02.04-88. Основания и фундаменты на вечномерзлых грунтах». М: Стандартинформ, 2019. $-40 \mathrm{c}$

8. СП 21.13330.2012 Здания и сооружения на подрабатываемых территориях и просадочных грунтах. Актуализированная редакция СНиП 2.01.09-91 (с Изменением № 1). - М: Стандартинформ, 2017. - 20 c

9. ГОСТ 25100-2011. Грунты. Классификация. - М: Стандартинформ, 2018. - 7 c.

10. Shamilov Kh.Sh., Sultanmagomedov S.M. Device for providing design position of underground main pipelines in permafrost soil // подземное закрепление участков трубопровода, а разработанная для ее расчета модель позволяет получить корректные выходные данные. Применение предложенной конструкции опор для закрепления участков газопровода исключает необходимость дорогостоящей надземной прокладки в тех случаях, когда участки мерзлоты носят прерывистый или островной характер, что существенно сокращает стоимость строительно-монтажных работ и последующие затраты на эксплуатацию.

Oil and geoecology: abstracts of I International School-seminar of Young Scientists and Students. - Baku: OGI, ANAS, 2018. P. 131-134.

11. Шамилов Х.Ш., Десяткин Д.П. Особенности проектирования трубопроводов в зонах распространения островной мерзлоты // Транспорт и хранение нефтепродуктов и углеводородного сырья. - 2019. - № 3. - С. 24-28.

12. Allen L.J. The Trans-Alaska pipeline. V. 2: South to Valdez. Seattle: Scribe Publishing Co., 1976 - 11 p.

13. Иваницкая Е.В. Опыт мониторинга уникального трансаляскинского нефтепровода // Наука и технологии трубопроводного транспорта нефти и нефтепродуктов. - 2011. - № 1 (1). С. 96-101.

14. Создание и реализация инновационных технологий строительства в проектах развития нефтепроводной структуры Западной Сибири: проекты «Пурпе-Самотлор», «ЗаполярьеПурпе» / Ю.В. Лисин, А.Н. Сапсай, В.И. Суриков, В.В. Павлов, А.Е. Сощенко, В.В. Бондаренко // Наука и технологии трубопроводного транспорта нефти и нефтепродуктов. 2013. - № 4 (12). - С. 6-11.

15. Конструктивные решения термостабилизаторов грунтов и оценка их эффективности для обеспечения твердомерзлого состояния грунтов оснований фундаментов при надземной прокладке трубопровода / А.Н. Сапсай, А.Е. Сощенко, Ю.Б. Михеев, Ю.В. Богатенков, В.В. Бондаренко // Наука и технологии трубопроводного транспорта нефти и нефтепродуктов. - 2014. - № 1 (13). - С. 36-41.

16. Shamilov Kh.Sh. Gumerov A.K. Sultanmagomedov S.M. Underground fastening of the trunk pipelines in areas of intermittent and insular permafrost // IOP Conference Series: Earth and Environmental Science. - 2020. - V. 459. - P. 032026. DOI: $10.1088 / 1755-1315 / 459 / 3 / 032026$

17. Определение и прогнозирование напряженнодеформированного состояния трубопровода с учетом грунтовых изменений в процессе эксплуатации / А.К. Гумеров, P.М. Каримов, Р.М. Аскаров, Х.Ш. Шамилов // Наука и техно- 
логии трубопроводного транспорта нефти и нефтепродуктов. - 2020. - № 10 (4). - С. 372-378.

18. Опора подвесная для участков подземной прокладки трубопроводов: пат. Рос. Федерация, № 2601651, заявл. 15.04.2015; опубл. 10.11.2016. Бюл. № 31 .

19. О закреплении подземных магистральных трубопроводов на болотах / Д.А. Гулин, Х.Ш. Шамилов, Р.Р. Хасанов, С.М. Султанмагомедов // Нефтегазовое дело. - 2015. - № 3. - С. 330-345.

20. Chai J.C., Hayashi S., Carter J.P. Vacuum consolidation and its combination with embankment loading // Canadian Geotechnical Journal. - 2006. - V. 43 (10). - P. 985-996.
21. Fioravante V. Load transfer from a raft to a pile with an interposed layer // Géotechnique. - 2010. - V. 61 (2). - P. 121-132.

22. Strength and mechanical behavior of short polypropylene fiber reinforced and cement stabilized clayey soil / C. Tang, B. Shi, W. Gao, F. Chen, Y. Cai // Geotextiles and Geomembranes. 2007. - V. 25. - № 3. - P. 194-202.

23. Устройство для обеспечения проектного положения подземного трубопровода при прокладке в условиях многолетнемерзлых грунтов: пат. Рос. Федерация, № 2643914, заявл. 01.12.2016; опубл. 06.02.2018. Бюл. № 4.

Поступила 25.11.2020 2.

\section{Информация об авторах}

Шамилов Х.Ш., ассистент кафедры гидрогазодинамики трубопроводных систем и гидромашин Уфимского государственного нефтяного технического университета.

Султанмагомедов Т.C., ассистент кафедры сооружения и ремонта газонефтепроводов и газонефтехранилищ Уфимского государственного нефтяного технического университета.

Султанмагомедов С.M., доктор технических наук, декан Факультета трубопроводного транспорта Уфимского государственного нефтяного технического университета. 
UDC 622.692.4.07

\title{
DESIGN OF THE SUPPORT FOR UNDERGROUND PIPELINE FASTENING IN CONDITIONS OF INSULAR AND DISCONTINUOUS PERMAFROST ZONES
}

\author{
Khiramagomed Sh. Shamilov 1 , \\ khiramagomed@mail.ru \\ Timur S. Sultanmagomedov 1 , \\ tsultanmaga@gmail.com \\ Sultanmagomed M. Sultanmagomedov ${ }^{1}$, \\ ftt2010@mail.ru \\ 1 Ufa State Petroleum Technological University, \\ 1, Kosmonavtov street, Ufa, 450064, Russia.
}

\begin{abstract}
The relevance of the study is caused by the need to develop the effective technologies to ensure the preservation of the design position of the main pipeline sections in the areas with permafrost distribution. The work is of particular relevance, taking into account active development of the northern and Arctic gas and oil regions of Russia.

The main aim of the research is to develop a design solution and the construction of underground supports for fixing non-heat-insulated sections of the pipeline in seasonally thawing and insular permafrost.

Objects: main pipeline fixed in frozen soils.

Results. The paper considers the existing types of supports and suspensions of pipelines in the context of their applicability for the fixing underground sections of oil and gas pipelines in permafrost and seasonally thawing soils, including at the intersection of insular permafrost, ice lenses and pingos. Based on the results of the analysis of the possible loads and limitations of existing supporting structures of pipelines with the risks of emersion and sagging of underground sections in the melted trench, the design of underground anchor supports is proposed and conclusions are made about the advantages of their use. To calculate the loads and determine the required dimensions and number of anchors, cross-sections of stretch ropes and a mounting clamp, a finite-element model was developed. Its effectiveness was confirmed analytically and experimentally on the developed test bench.
\end{abstract}

\section{Key words:}

Pipeline anchor support, structural design, underground pipelining, intermittent permafrost, seasonal thawing soils, ice lenses, pingos, stability.

\section{REFERENCES}

1. Chadburn S.E., Burke E., Cox P., Friedlingstein P., Hugelius G., Westermann S. An observation based constraint on permafrost loss as a function of global warming. Nature Climate Change, 2017, vol. 7, Iss. 5, pp. 340-344.

2. Yanhui You, Qihao Yu, Xicai Pan, Xinbin Wang, Lei Guo, Geophysical imaging of permafrost and talik configuration beneath a thermokarst lake. Permafrost and Periglacial Processes, 2017, vol. 28, pp. 470-476.

3. Lewkowicz A.G., Way R.G. Extremes of summer climate trigger thousands of thermokarst landslides in a high Arctic environment. Nature Communications, 2019, vol. 10 (1):1329. Available at: https://doi.org/10.1038/s41467-019-09314-7 (accessed 17 April 2020).

4. Ford J.D., McDowell G., Jones J. The state of climate change adaptation in the Arctic. Environmental Research Letters, 2014, vol. 9 (104005). Available at: https://iopscience.iop.org/article/ 10.1088/1748-9326/9/10/104005 (accessed 17 April 2020).

5. Van Huissteden J. Thawing permafrost: permafrost carbon in a warming Arctic. Cham, Springer Nature Switzerland AG, 2020. 39 p

6. SP 36.13330.2012 Magistralnye truboprovody. Aktualizirovannaya redaktsiya SNiP 2.05.06-85* (s Izmeneniyami No 1,2) [SP 36.13330.2012 Main pipelines. Updated version of SN\&P 2.05.06-85 * (with amendments No. 1, 2)]. Moscow, Standartinform Publ., 2019. 46 p.

7. SP 25.13330.2012 Svod pravil «SNiP 2.02.04-88. Osnovaniya fundamenty na vechnomerzlykh gruntakh» [SP 25.13330.2012 Code of practice «SNiP 2.02.04-88. Foundations on permafrost»]. Moscow, Standartinform Publ., 2019. 40 p.

8. SP 21.13330.2012 Zdaniya i sooruzheniya na podrabatyvayemykh territoriyakh $i$ prosadochnykh gruntakh. Aktualizirovannaya redaktsiya SNiP 2.01.09-91 (s Izmeneniem No 1) [SP 21.13330.2012 Buildings and structures in the developed areas and subsidence soils. The updated version of SN\&P 2.01.09-91 (with amendment No. 1)]. Moscow, Standartinform Publ., 2017. 20 p.
9. GOST 25100-2011. Grunty. Klassifikatsiya [State Standard 251002011. Soils. Classification]. Moscow, Standartinform Publ., 2018. $7 \mathrm{p}$.

10. Shamilov Kh.Sh., Sultanmagomedov S.M. Device for providing design position of underground main pipelines in permafrost soil. Proc. of I International School-seminar of Young Scientists and Students. Baku, 2018. pp. 131-134.

11. Shamilov Kh.Sh., Desyatkin D.P. Designing pipelines in zones of intermittent and insular permafrost. Transport and Storage of Oil Products and Hydrocarbons, 2019, vol. 3, pp. 24-28. In Rus.

12. Allen L.J. The Trans-Alaska pipeline. Vol 2: South to Valdez. Seattle, Scribe Publishing Co., 1976. 11 p.

13. Ivanitskaya E.V. The experience of monitoring a unique TransAlaskan oil pipeline. Nauka i tekhnologii truboprovodnogotransporta nefti i nefteproduktov, 2011, vol. 1 (1), pp. 96-101. In Rus.

14. Lisin Yu.V., Sapsay A.N., Surikov V.I., Pavlov V.V., Soshchenko A.E. Bondarenko V.V. Creation and implementation of innovative construction technologies in projects for the development of the oil pipeline structure in Western Siberia: Purpe-Samotlor and PolarPurpe projects. Nauka i tekhnologii truboprovodnogo transporta nefti i nefteproduktov, 2013, vol. 4 (12), pp. 6-11. In Rus.

15. Sapsay A.N., Soshchenko A.E., Mikheev Yu.B., Bogatenkov Yu.V., Bondarenko V.V. Constructive solutions of soil thermal stabilizers and evaluation of their effectiveness to ensure the frozen state of soils of the foundations for above-ground pipeline laying. Nauka $i$ tekhnologii truboprovodnogo transporta nefti $i$ nefteproduktov, 2014, vol. 1 (13), pp. 36-41. In Rus.

16. Shamilov Kh.Sh. Gumerov A.K. Sultanmagomedov S.M. Underground fastening of the trunk pipelines in areas of intermittent and insular permafrost. IOP Conference Series: Earth and Environmental Science, 2020, vol. 459, pp. 032026. DOI: $10.1088 / 1755-1315 / 459 / 3 / 032026$ 
17. Gumerov A.K., Karimov R.M., Askarov R.M., Shamilov Kh.Sh. Determination and prediction of the stress-strain state of pipeline, taking into account soil changes during operation. Science \& technologies: oil and oil products, 2020, vol. 10, no. 4, pp. 372-378.

18. Revel-Muroz P.A., Lisin Yu.V., Soshchenko A., Bronennikov V.A., Bondarenko V.V., Surikov V.I., Mikheyev Yu.B., Shonin K.S. Opora podvesnaya dlya uchastkov podzemnoy prokladki truboprovodov [Suspension support for underground pipelines]. Patent RF, no. 2601651, 2016.

19. Gulin D.A., Shamilov Kh.Sh., Khasanov R.R., Sultanmagomedov S.M About fixing underground trunk pipelines in swamps. Neftegazovoye delo, 2015, vol. 3, pp. 330-345. In Rus.

20. Chai J.C., Hayashi S., Carter J.P. Vacuum consolidation and its combination with embankment loading. Canadian Geotechnical Journal, 2006, vol. 43 (10), pp. 985-996.
21. Fioravante V. Load transfer from a raft to a pile with an interposed layer. Géotechniqu, 2010, vol. 61 (2), pp. 121-132.

22. Tang C., Shi B., Gao W., Chen F., Cai Y. Strength and mechanical behavior of short polypropylene fiber reinforced and cement stabilized clayey soil. Geotextiles and Geomembranes, 2007, vol. 25, no. 3, pp. 194-202.

23. Shamilov Kh.Sh., Sultanmagomedov S.M., Khasanov R.R., Sultanmagomedov T.S., Gulin D.A. Ustroystvo dlya obespecheniya proektnogo polozheniya podzemnogo truboprovoda pri prokladke $v$ usloviyakh mnogoletnemerzlykh gruntov [A device for ensuring the design position of an underground pipeline when laying in permafrost soils]. Patent RF, no. 2643914, 2018.

Received: 25 November 2020.

\section{Information about the authors}

Khiramagomed Sh. Shamilov, assistant, Ufa State Petroleum Technological University.

Timur S. Sultanmagomedov, assistant, Ufa State Petroleum Technological University.

Sultanmagomed M. Sultanmagomedov, Dr. Sc., Dean of the Faculty of Pipeline Engineering, Ufa State Petroleum Technological University. 